\title{
PERFORMANCE ANALYSIS OF THE FRACTIONAL-ORDER VEHICLE MECHATRONIC ISD SUSPENSION WITH PARAMETER PERTURBATION
}

\author{
Yujie Shen, Jie Hua, Qianhe Hou \\ Automotive Engineering Research Institute, Jiangsu University, Zhenjiang, China \\ e-mail: shenyujie@ujs.edu.cn; huajie0214@163.com; hqh873149415@126.com \\ XiAOHUA XIA \\ Key Laboratory of Road Construction Technology and Equipment, Chang'an University, Xi'an, China \\ e-mail:xhxia@chd.edu.cn \\ Yanling LiU, XiaOfeng Yang \\ Automotive Engineering Research Institute, Jiangsu University, Zhenjiang, China \\ e-mail: liuyl@ujs.edu.cn; yangxf18@ujs.edu.cn
}

\begin{abstract}
This paper concerns the performance analysis of a fractional-order vehicle mechatronic ISD suspension with parameter perturbation. A dynamic model of the vehicle mechatronic ISD suspension based on a fractional-order electrical network is constructed. The superiority of the vibration isolation performance of the fractional-order ISD suspension is demonstrated, and the dynamic performance of the suspension is analyzed considering perturbation of parameters. Results show that the inertance has an important role when the frequency is above $10^{3} \mathrm{~Hz}$, and the fractional inductance order and fractional capacitance order have significant impact in the frequency range of $10^{-2} \mathrm{~Hz}$ to $10^{2} \mathrm{~Hz}$.
\end{abstract}

Keywords: vehicle suspension, mechatronic inerter, fractional order, parameter perturbation

\section{Introduction}

Suspension is an important part of the vehicle chassis system, its performance directly affects the performance of the vehicle in the driving process (Zhang et al., 2016; Yan et al., 2018; Fu and Dong, 2021). With the development of automobile industry, the performance of traditional passive suspension is difficult to meet people's higher requirements because of its non-adjustable parameters. Due to the problems of high cost, high energy consumption and complex control, the promotion of active and semi-active suspension (Zhang et al., 2015; Huang et al., 2014; He et al., 2020) is limited. As inerter (Smith, 2002) breaks the restriction of the traditional "spring-damper" suspension system, and a new "inerter-spring-damper" suspension (called ISD suspension) structure has widened the new suspension research field for domestic and foreign scholars. Research shows that the vibration isolation performance of the vehicle suspension system can be greatly improved by employing an inerter element (Chen et al., 2014; Wang et al., 2017; Li et al., 2021).

The inerter can be implemented in many ways, such as a rack-and-pinion inerter (Papageorgiou and Smith, 2005; Karthik and James, 2018; Wang et al., 2014), ball-screw inerter (Papageorgiou et al., 2009; Siami and Karimi, 2020; He et al., 2017), hydraulic-based inerter (Wang et al., 2011; Shen et al., 2019; Liu et al., 2019) and fluid-based inerter (Swift et al., 2013; Wagg and Pei, 2020; Liu et al., 2018). On this basis, a mechatronic inerter is obtained by coupling a mechanical-based inerter device with a rotating motor (Wang et al., 2011), which can effectively solve the high complexity of the mechanical network by using the function of electrical components to simulate the impedance of the corresponding mechanical components. 
At the same time, the concept of a fractional order inerter and damper is proposed (Chen et al., 2020), which further improves the practical application ability of the mechatronic inerter. For many complicated systems, fractional-order mathematical description could reflect the dynamic behavior better and more accurately than that using the integer-order way (Nguyen et al., 2021; Memlikai et al., 2021). The research of the vehicle ISD suspension is a multi-variable and multi-objective suspension design problem, and the design of component parameters needs to meet the requirements of ride comfort and handling stability. The previous work concentrated on the integer-order electrical network using the mechatronic inerter element, and this paper creatively applies the fractional-order theory to the vehicle mechatronic ISD suspension. That is, based on the fractional-order vehicle mechatronic ISD suspension employing the ball-screw mechatronic inerter, the influence of parameter perturbation on the suspension performance is studied, which provides a reference for the parameter design of the fractional-order suspension.

This paper is arranged as follows. In Section 2, the definition of fractional calculus and its analytical expression are introduced. In Section 3, based on the ball-screw type mechatronic inerter, the dynamic model of the quarter car is established and detailed parameters of the suspension system are given. The influence of the parameters perturbation on the vehicle suspension performance is discussed in detail in Section 4. Some conclusions are drawn in Section 5.

\section{Fractional-order expressions for network elements}

The basic operator of fractional calculus is $t_{0} D_{t}^{\alpha}$ (Podlubny, 1999), where $t_{0}$ and $t$ are the lower and upper bounds of the operator, $\alpha$ is the order of calculus, which is defined as follows

$$
D_{t}^{\alpha}= \begin{cases}\frac{d^{\alpha}}{d t^{\alpha}} f(t) & \text { for } \quad \alpha>0 \\ f(t) & \text { for } \quad \alpha=0 \\ \int_{t_{0}}^{t} f(\tau) d \tau^{-\alpha} & \text { for } \quad \alpha<0\end{cases}
$$

Thus, the fractional-order calculus expressions of mechanical network elements (inerter, spring and damper) and electrical network elements (capacitor, inductor and resistor) are displayed in Table 1.

Table 1. Comparison table of the fractional mechanical and electrical network elements

\begin{tabular}{|lc|lc|}
\hline \multicolumn{2}{|l|}{ Mechanical network elements } & \multicolumn{1}{|c|}{ Electrical network elements } \\
\hline \hline Spring & $\frac{d^{\alpha} F}{d t^{\alpha}}=k\left(v_{2}-v_{1}\right)$ & Inductor & $\frac{d^{\alpha} i}{d t^{\alpha}}=\frac{1}{L}\left(V_{2}-V_{1}\right)$ \\
\hline Damper & $F=c\left(v_{2}-v_{1}\right)$ & Resistor & $i=\frac{1}{R}\left(V_{2}-V_{1}\right)$ \\
\hline Inerter & $F=b \frac{d^{\beta}\left(v_{2}-v_{1}\right)}{d t^{\beta}}$ & Capacitor & $i=C \frac{d^{\beta}\left(V_{2}-V_{1}\right)}{d t^{\beta}}$ \\
\hline
\end{tabular}

In Table 1, $F$ is the force which is applied at two terminals of the mechanical network element, $k$ is the spring stiffness, $i$ is the current flowing through the electrical network elements, $L$ is the inductance, $V_{1}$ and $V_{2}$ are voltages crossing the two terminals of the electrical network elements, $c$ is the damper coefficient, $v_{1}$ and $v_{2}$ are velocities of the two terminals, $R$ is the resistance, $b$ is the inertance, $C$ is the capacitance. Based on the 'force-current' electromechanical similarity theory, the fractional order expressions of the force to velocity type impedance transfer function of mechanical network elements are: $k / s^{\alpha}, c$ and $b s^{\beta}$. The corresponding fractional order expressions of electrical network elements are: $1 / L s^{\alpha}, 1 / R$ and $C s^{\beta}$, in which $s$ is the Laplace variable. 


\section{Model of the vehicle fractional-order mechatronic ISD suspension}

In this Section, the mechatronic inerter and the vehicle fractional-order mechatronic ISD suspension system model will be introduced in detail.

\subsection{Mechatronic inerter}

In this paper, a ball-screw mechatronic inerter composed of a ball-screw inerter and rotary motor is considered as shown in Fig. 1.
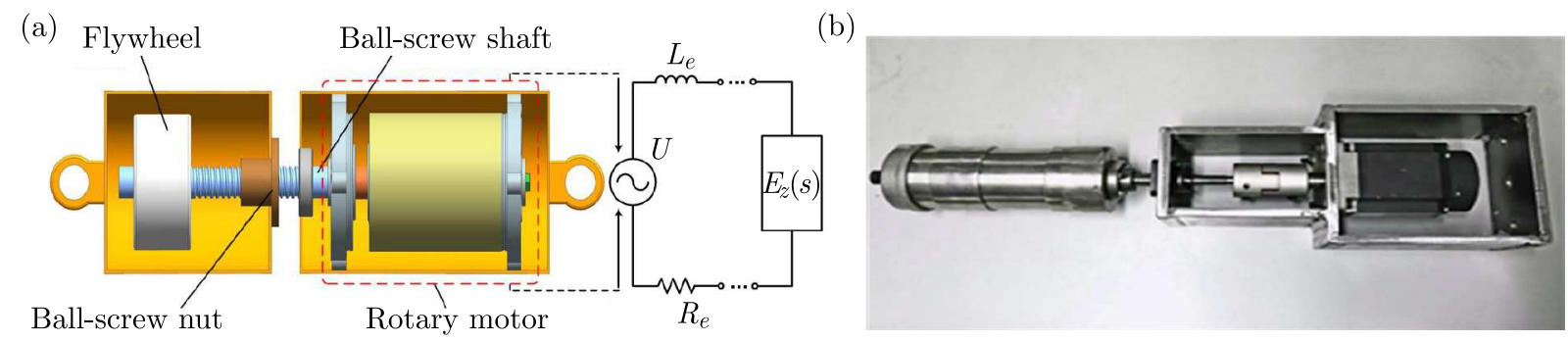

Fig. 1. Schematic diagram and physical drawing of the ball-screw mechatronic inerter: (a) schematic of ball-screw inerter, (b) prototype of the ball-screw mechatronic inerter

According to Fig. 1, the flywheel and the ball-screw rotate coaxially with the rotor of the rotary motor, and the ball-screw nut meshing with the ball-screw is fixed in the working cylinder. Changing the rotational inertia of the flywheel can alter the inertance of the ball-screw mechatronic inerter. The rotary motor generates AC terminal voltage in the working process, which is coupled with the electrical network impedance of the external electrical circuit. The equivalent resistor $R_{e}$ and inductor $L_{e}$ of the rotary motor can be neglected when analyzing the force to velocity type impedance transfer function $B(s)$ of the mechatronic inerter, so the expression of $B(s)$ is shown as follows

$$
B(s)=b s+\left(\frac{2 \pi}{P}\right)^{2} \frac{k_{t} k_{e}}{Z_{e}(s)}
$$

In Eq. (3.1), $b$ is the inertance of the ball-screw mechatronic inerter, $P$ is the pitch of the ball-screw mechanism, $k_{e}$ is the induced electromotive force coefficient of the rotary motor, $k_{t}$ is the thrust coefficient of the rotary motor. $Z_{e}(s)$ is the impedance expression of the external electrical network of the rotary motor. In this external electrical network, the resistor is connected in parallel with the inductor, and then in series with the capacitor. Thus, the expression of velocity impedance is presented as

$$
Z_{e}(s)=\frac{1}{\frac{1}{\frac{1}{L_{e} s^{\alpha}}+\frac{1}{R_{e}}}+\frac{1}{C_{e} s^{\beta}}}
$$

where $L_{e}$ is the fractional-order inductor coefficient, $R_{e}$ is the resistor coefficient, $C_{e}$ is the fractional-order capacitor coefficient, $\alpha$ is the fractional order of the inductor, $\beta$ is the fractional order of the capacitor.

\subsection{Vehicle fractional-order mechatronic ISD suspension}

A 2-DOF physical model considering vertical motion of the sprung mass and unsprung mass is a representative dynamic model which is widely used to investigate the vertical dynamic performance of the suspension system. In this paper, a two-degree suspension dynamic model is established as shown in Fig. 2 considering the vibration of both the sprung mass and unsprung mass of the vehicle. 


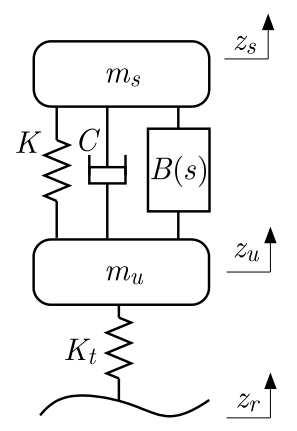

Fig. 2. Quarter car model

In Fig. 2, $K$ is the stiffness of the support spring, $C$ is the damper coefficient, $K_{t}$ is the equivalent spring stiffness of the tire, $m_{s}$ is the sprung mass, $m_{u}$ is the unsprung mass, $z_{s}, z_{u}$ and $z_{r}$ are the vertical displacements of the sprung mass, unsprung mass and the random road input, respectively. $B(s)$ is the impedance expression of the mechatronic inerter. The dynamic equations of the quarter-car model are expressed as

$$
\begin{aligned}
& m_{s} \ddot{z}_{s}+K\left(z_{s}-z_{u}\right)+C\left(\dot{z}_{s}-\dot{z}_{u}\right)+B(s)\left(\dot{z}_{s}-\dot{z}_{u}\right)=0 \\
& m_{u} \ddot{z}_{u}+K_{t}\left(z_{u}-z_{r}\right)-K\left(z_{s}-z_{u}\right)-C\left(\dot{z}_{s}-\dot{z}_{u}\right)-B(s)\left(\dot{z}_{s}-\dot{z}_{u}\right)=0
\end{aligned}
$$

According to the kinematic analysis of the sprung and unsprung mass, the dynamic Laplace equation of the quarter car suspension vibration model is obtained

$$
\begin{aligned}
& m_{s} s^{2} Z_{s}+[K+C s+s B(s)]\left(Z_{s}-Z_{u}\right)=0 \\
& m_{u} s^{2} Z_{u}-[K+C s+s B(s)]\left(Z_{s}-Z_{u}\right)+K_{t}\left(Z_{u}-Z_{r}\right)=0
\end{aligned}
$$

where $Z_{s}, Z_{u}$ and $Z_{r}$ are Laplace transforms of $z_{s}, z_{u}$ and $z_{r}$, respectively. The parameters of the quarter car model are shown in Table 2.

Table 2. Model parameters

\begin{tabular}{|l|c|}
\hline \multicolumn{1}{|c|}{ Parameters } & Values \\
\hline \hline Sprung mass $m_{s}[\mathrm{~kg}]$ & 320 \\
\hline Unsprung mass $m_{u}[\mathrm{~kg}]$ & 45 \\
\hline Spring stiffness $K[\mathrm{~N} / \mathrm{m}]$ & 22000 \\
\hline Damper coefficient $C[\mathrm{Ns} / \mathrm{m}]$ & 1000 \\
\hline Tire stiffness $K_{t}[\mathrm{~N} / \mathrm{m}]$ & 190000 \\
\hline
\end{tabular}

In order to obtain the optimal setting of suspension model parameters, under the conditions of random road input, taking the RMS (root-mean-square) value of vehicle body acceleration, the RMS value of the suspension working space and the RMS value of the dynamic tire load as the optimization objectives, the inertance $b$, resistance coefficient $R_{e}$, fractional-order inductance coefficient $L_{e}$, fractional inductance order $\alpha$, fractional-order capacitance coefficient $C_{e}$ and fractional capacitance order $\beta$ are selected as the optimization variables. Under the constraint that all optimization variables are non negative and the two fractional orders are not greater than 1, the proposed approach (Shen et al., 2019b) is used to optimize the parameters, and the results are shown in Table 3.

Compared with the traditional passive suspension and the integer-order electrical network-based vehicle mechatronic ISD suspension, the performance indexes are shown in Table 4, and the responses of the fractional-order electrical network-based vehicle mechatronic ISD suspension are shown in Figs 3-5. 
Table 3. Optimized parameters

\begin{tabular}{|l|c|}
\hline \multicolumn{1}{|c|}{ Parameters } & Values \\
\hline \hline Inertance $b[\mathrm{~kg}]$ & 6 \\
\hline Resistance coefficient $R_{e}[\Omega]$ & 29.4 \\
\hline Fractional-order inductance coefficient $L_{e}[\mathrm{H}]$ & 1.33 \\
\hline Fractional inductance order $\alpha$ & 0.6 \\
\hline Fractional-order capacitance coefficient $C_{e}[\mathrm{~F}]$ & 0.04 \\
\hline Fractional capacitance order $\beta$ & 0.3 \\
\hline
\end{tabular}

Table 4. Performance indexes of vehicle suspension

\begin{tabular}{|l|c|c|c|c|c|}
\hline RMS values & $\begin{array}{c}\text { Passive } \\
\text { suspension }\end{array}$ & $\begin{array}{c}\text { Integer-order } \\
\text { ISD suspension }\end{array}$ & $\begin{array}{c}\text { Improve- } \\
\text { ment }\end{array}$ & $\begin{array}{c}\text { Fractional-order } \\
\text { ISD suspension }\end{array}$ & $\begin{array}{c}\text { Improve- } \\
\text { ment }\end{array}$ \\
\hline \hline $\begin{array}{l}\text { Vehicle body } \\
\text { acceleration }\left[\mathrm{m} / \mathrm{s}^{2}\right]\end{array}$ & 2.9283 & 2.9184 & $0.34 \%$ & 2.8885 & $1.36 \%$ \\
\hline $\begin{array}{l}\text { Suspension } \\
\text { working space }[\mathrm{m}]\end{array}$ & 0.0291 & 0.0226 & $22.34 \%$ & 0.0198 & $31.96 \%$ \\
\hline $\begin{array}{l}\text { Dynamic tire } \\
\text { load }[\mathrm{N}]\end{array}$ & 2013.5 & 1958.5 & $2.73 \%$ & 1822.9 & $9.47 \%$ \\
\hline
\end{tabular}

(a)

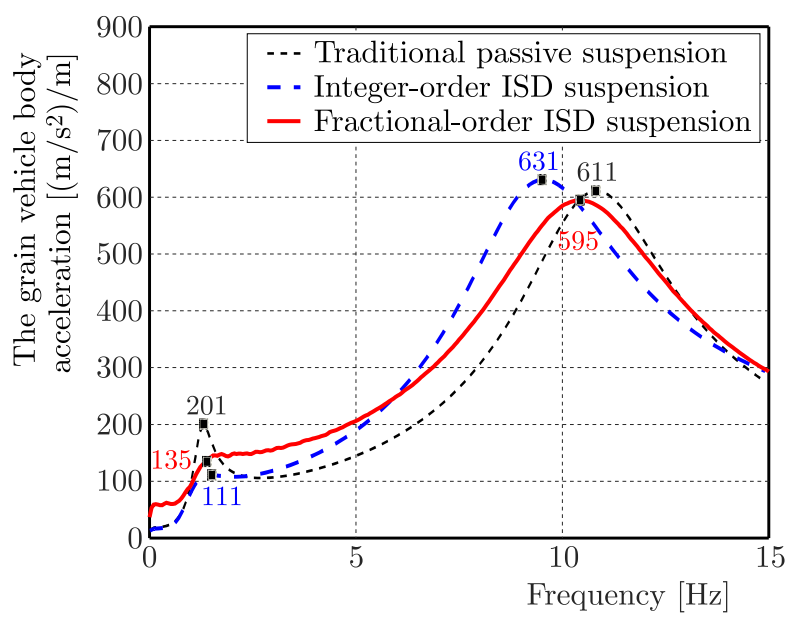

(b)

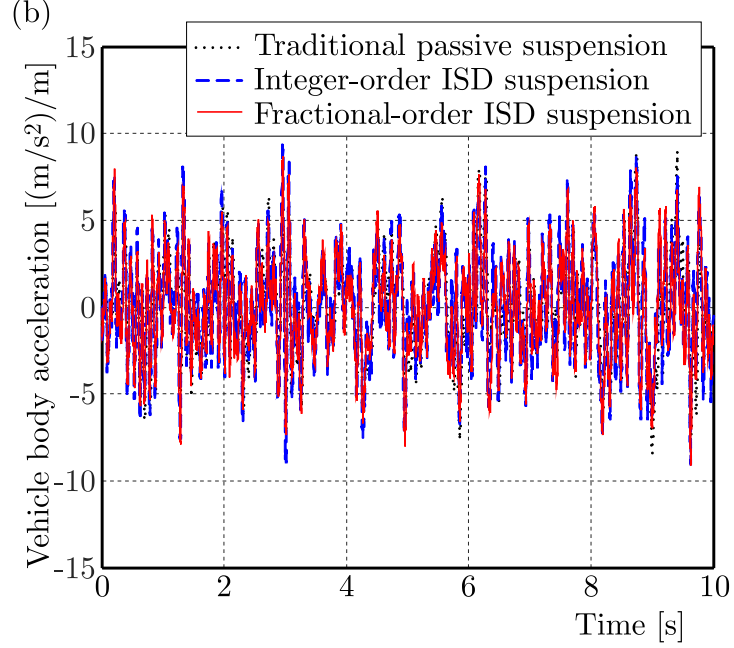

Fig. 3. Responses of vehicle body acceleration

(a)

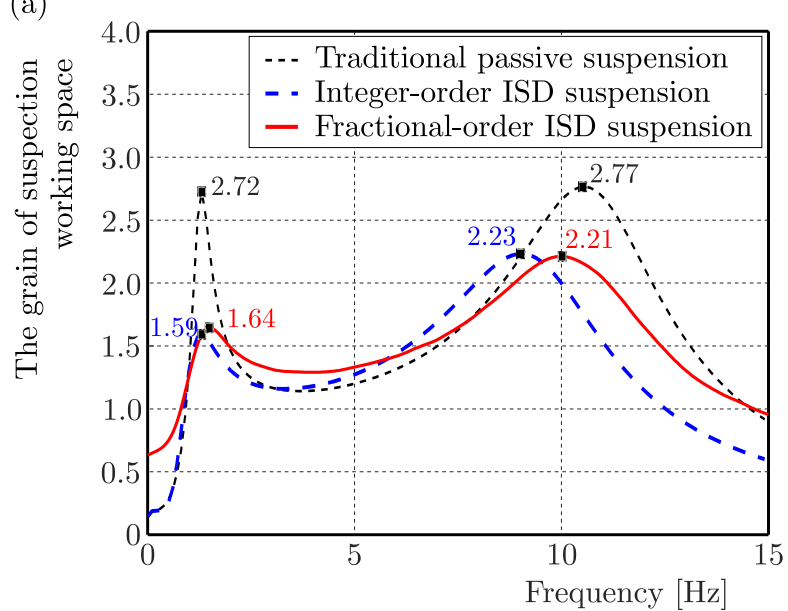

(b)

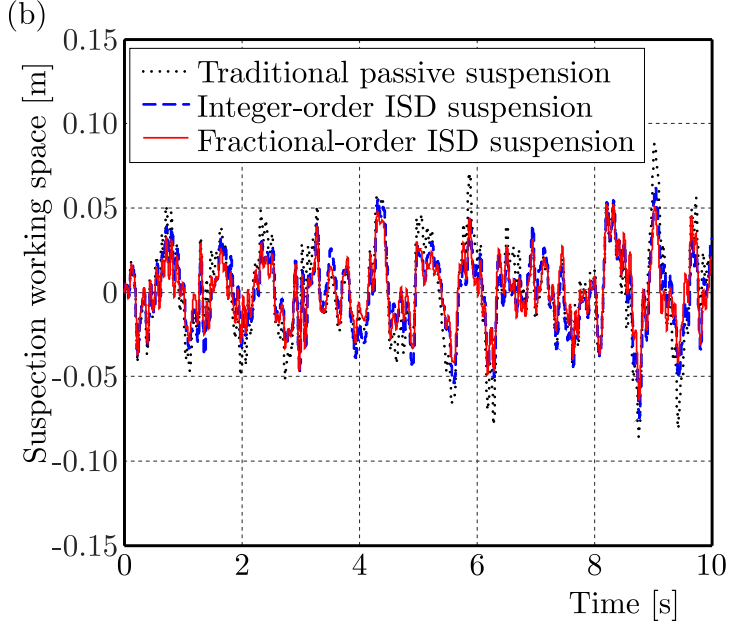

Fig. 4. Responses of suspension working space 

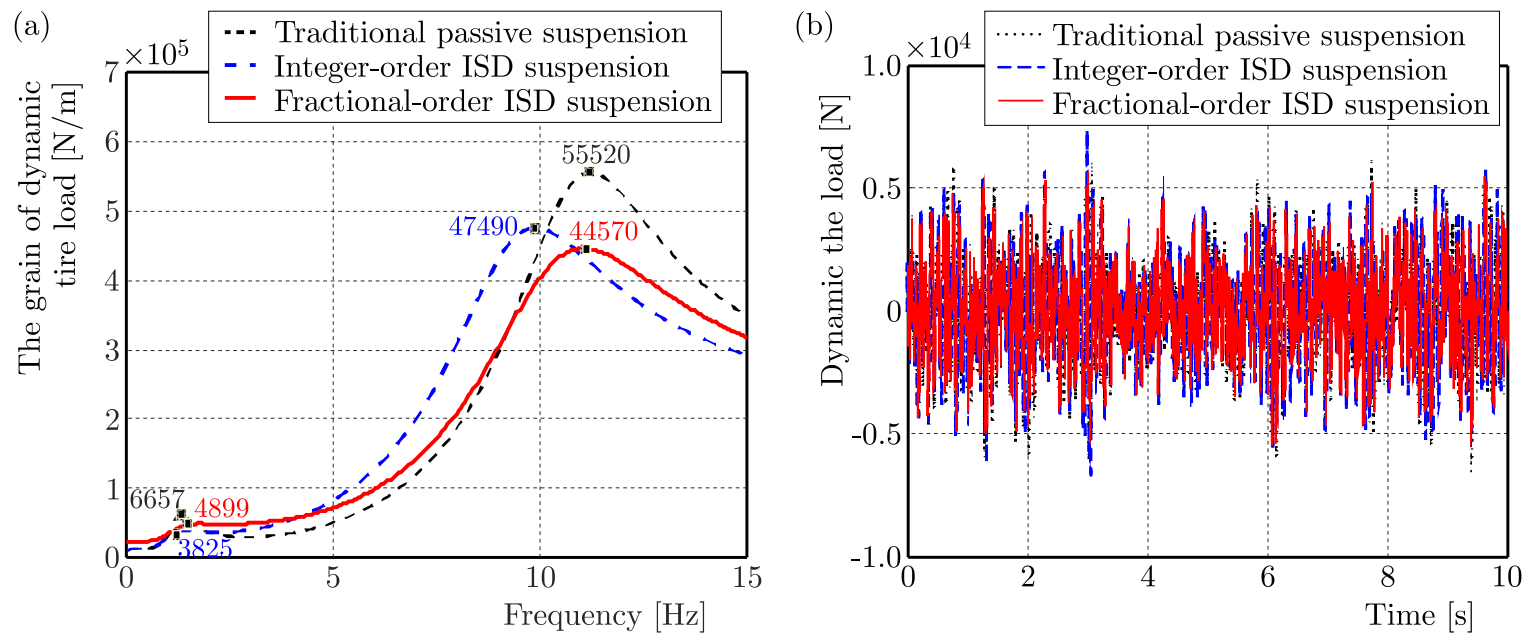

Fig. 5. Responses of dynamic tire load

It can be seen that, compared to the traditional passive suspension and the integer-order ISD suspension, the vibration isolation performance of the fractional-order ISD suspension is significantly improved. In the frequency analysis, high frequency resonance peaks of the body acceleration gain, suspension working space gain and tire dynamic load gain are lower than those of the traditional passive suspension and integer-order ISD suspension, while the low frequency resonance peaks are lower than those of traditional passive suspension and slightly higher than those of integer-order ISD suspension. In the time domain performance index, the RMS values of body acceleration, suspension working space and dynamic tire load are improved by $1.36 \%$, $31.96 \%$ and $9.47 \%$, respectively. It is worth noting that the fractional-order ISD suspension is superior to the integer-order ISD suspension and passive suspension in terms of the suspension working space and dynamic tire load, but the improvement is relatively small in terms of body acceleration.

\section{Impact of parameters perturbation on vehicle suspension performance}

In this Section, the impact of parameters perturbation on the vehicle suspension performance will be analyzed in detail. Inertance $b$, fractional inductance order $\alpha$ and fractional capacitance order $\beta$ are selected as the objects of analysis. According to the parameter optimization results, their reference values are increased and decreased by $50 \%$, and other parameters remain unchanged, as shown in Table 5.

Table 5. Perturbation parameters

\begin{tabular}{|l|c|c|c|}
\hline Parameters of mechatronic inerter & Reference value & $-50 \%$ & $+50 \%$ \\
\hline \hline Inertance $b[\mathrm{~kg}]$ & 6 & 3 & 9 \\
\hline Fractional inductance order $\alpha$ & 0.6 & 0.3 & 0.9 \\
\hline Fractional capacitance order $\beta$ & 0.3 & 0.15 & 0.45 \\
\hline
\end{tabular}

\subsection{Effect of inertance $b$}

When inertance $b$ changes, Fig. 6 shows the comparison of Bode diagrams of the suspension system, and Fig. 7 shows the change trend of RMS values of body acceleration, suspension working space and dynamic tire load. 

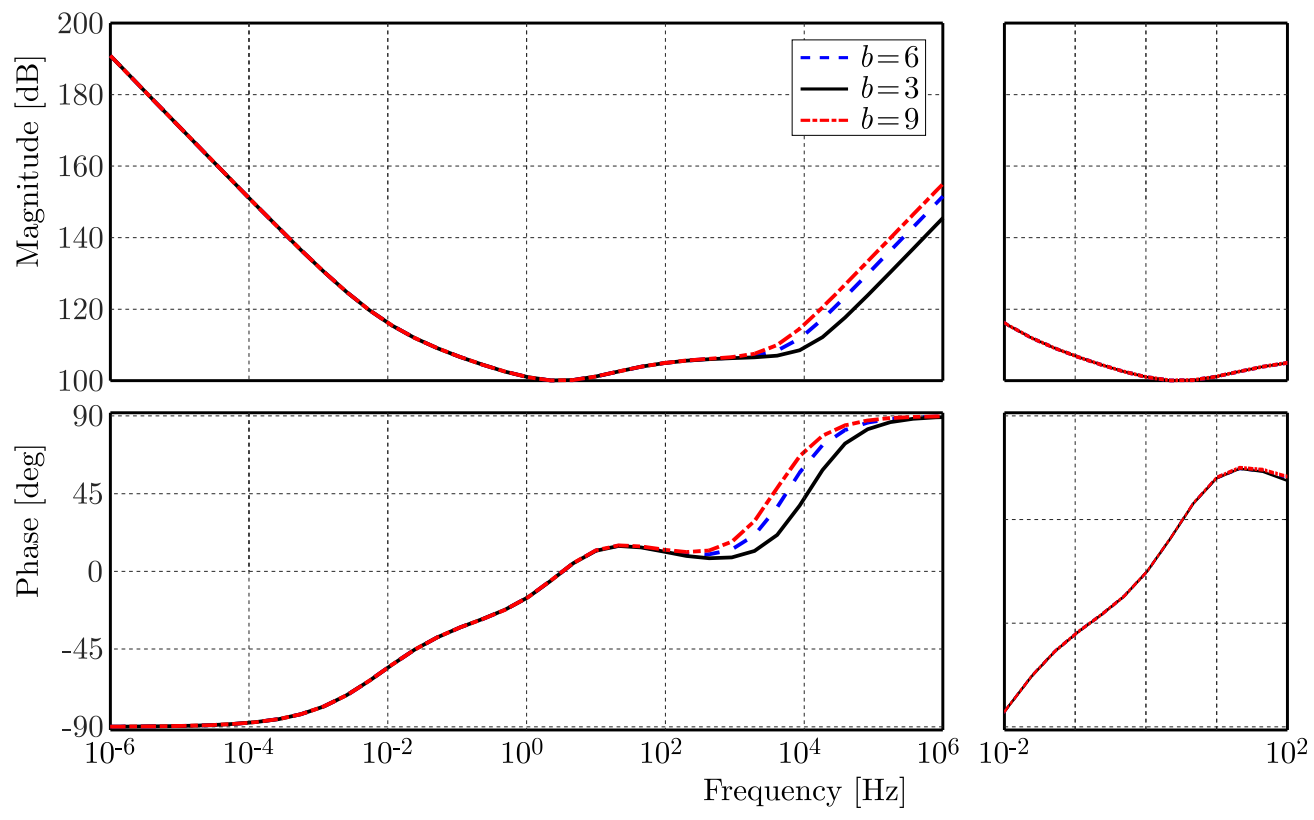

Fig. 6. Comparison of Bode diagrams (a) with different inertance (b)

(a)

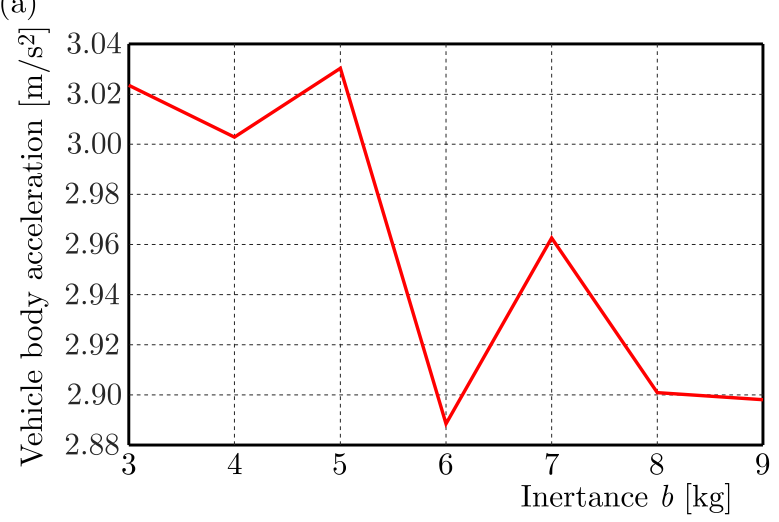

(b)

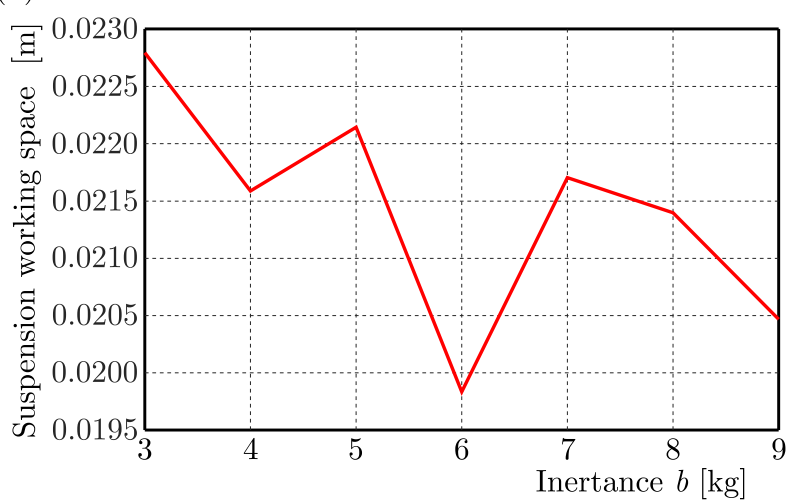

(c)

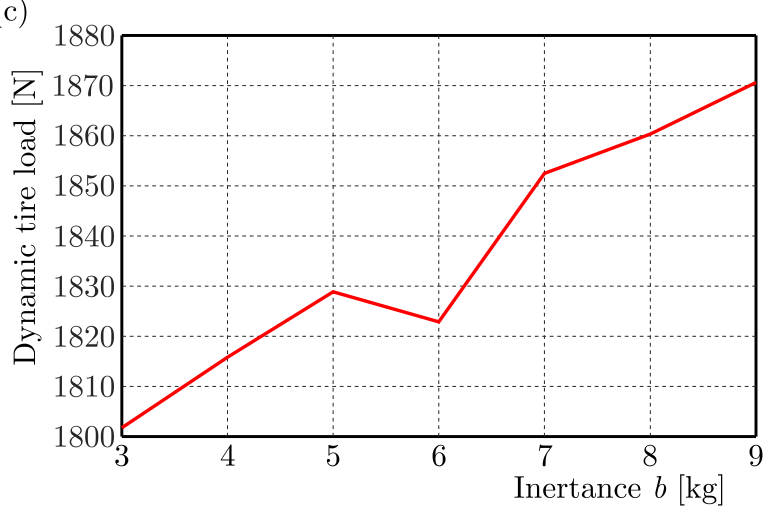

Fig. 7. Impact of inertance on the time domain index

According to the magnitude and phase, when the frequency is above $10^{3} \mathrm{~Hz}$, the inertance $b$ is dominant. When the inertance $b$ increases, the magnitude increases, and its linear shape is like the inerter form. Such a form does not exist in the traditional passive suspension, which is a prominent feature of the vehicle ISD suspension. At the same time, in the frequency range of $10^{-2} \mathrm{~Hz}$ to $10^{2} \mathrm{~Hz}$, which is most common in automobile engineering, a change in the inertance $b$ 
has little effect on the magnitude and phase. The change trend of RMS values generally presents a fluctuating state, but when the inertance $b$ is $6 \mathrm{~kg}$, the RMS values all reach the extreme point, showing local optimization, which is consistent with the optimization results.

\subsection{Effect of fractional inductance order $\alpha$}

When the fractional inductance order $\alpha$ changes, Fig. 8 shows the comparison of Bode diagrams of the suspension system, and Fig. 9 shows the change trend of RMS values of body acceleration, suspension working space and dynamic tire load.

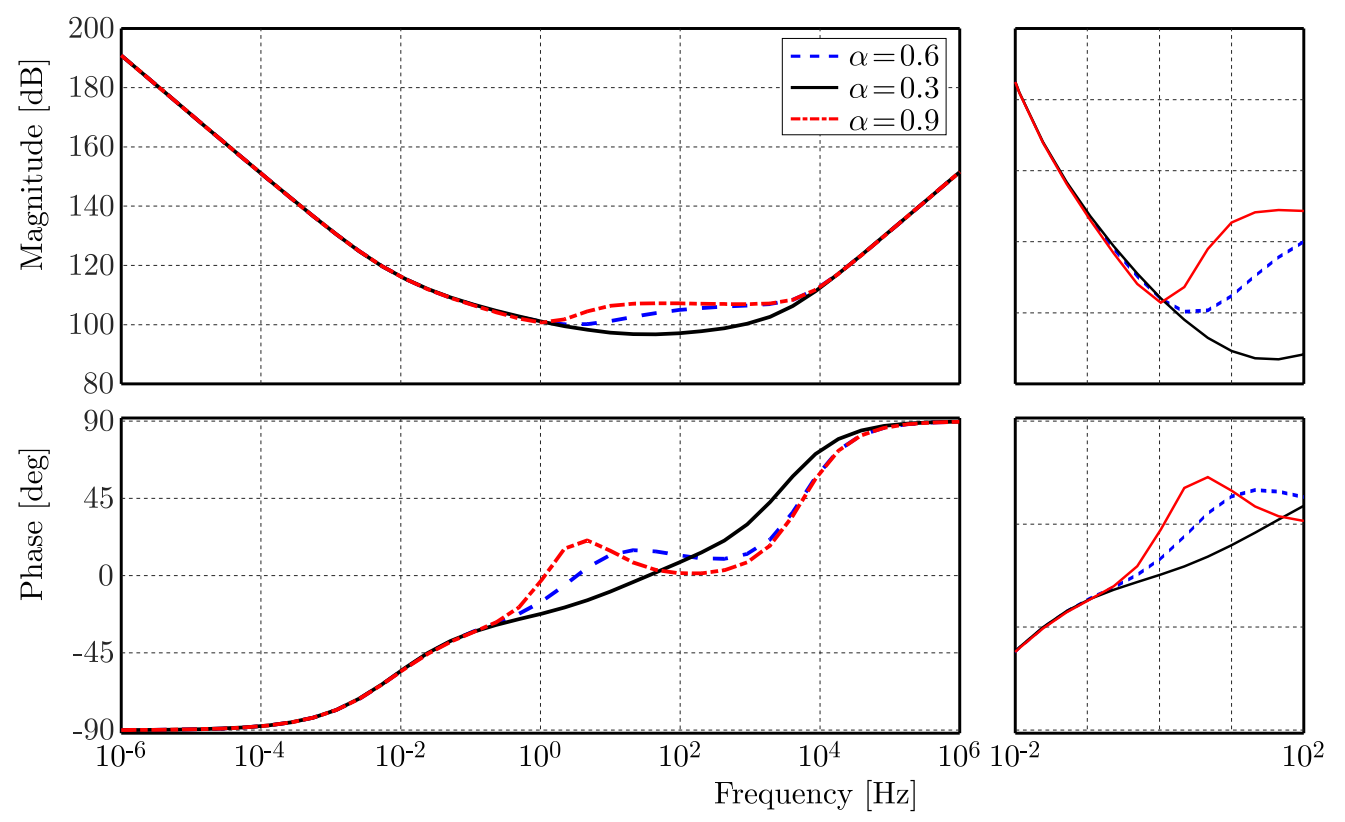

Fig. 8. Comparison of Bode diagrams (a) with different fractional inductance orders (b)

According to the magnitude and phase, when the frequency is between $10^{0} \mathrm{~Hz}$ and $10^{4} \mathrm{~Hz}$, the effect of the fractional inductance order $\alpha$ is dominant. When the fractional inductance order $\alpha$ increases, the magnitude increases. At the same time, in the frequency range of $10^{-2} \mathrm{~Hz}$ to $10^{2} \mathrm{~Hz}$, the larger the fractional inductance order $\alpha$ is, the bigger is the magnitude. From the change trend of RMS values, it can be seen that when the fractional inductance order $\alpha$ is less than 0.8 , the RMS values do not change significantly. When the fractional inductance order $\alpha$ is greater than 0.8 , the RMS values increase rapidly with the increase of the order.

\subsection{Effect of fractional capacitance order $\beta$}

When the fractional capacitance order $\beta$ changes, Fig. 10 shows the comparison of Bode diagrams of the suspension system, and Fig. 11 shows the change trend of RMS values of body acceleration, suspension working space and dynamic tire load.

From the magnitude and phase, it can be seen that when the fractional capacitance order $\beta$ changes, the magnitude will be affected in the range of $10^{-4} \mathrm{~Hz}$ to $10^{4} \mathrm{~Hz}$, and the larger the fractional capacitance order $\beta$ is, the bigger is the amplitude in the range of $10^{-4} \mathrm{~Hz}$ to $10^{-1} \mathrm{~Hz}$, and the smaller it is in the range of $10^{-1} \mathrm{~Hz}$ to $10^{4} \mathrm{~Hz}$. It is worth noting that the change of fractional capacitance order $\beta$ has a significant impact in the range of $10^{-2} \mathrm{~Hz}$ to $10^{2} \mathrm{~Hz}$ which is most observed in the automobile engineering. From the change trend of RMS values, it can be seen that the RMS value of suspension working space reaches the extreme value when the 
(a)

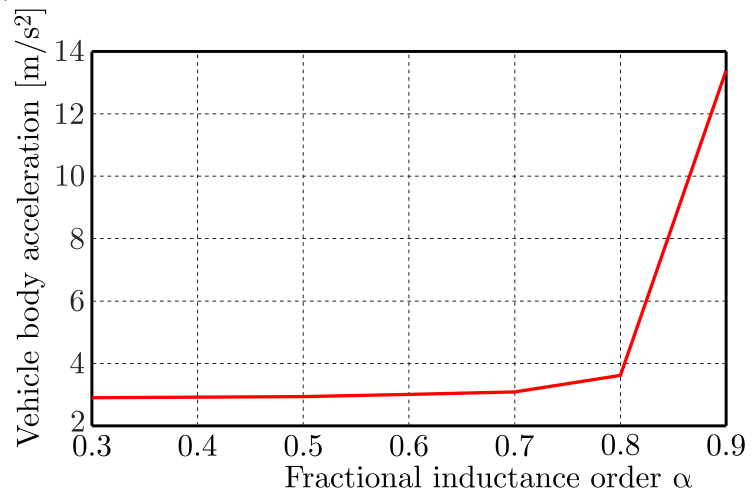

(b)

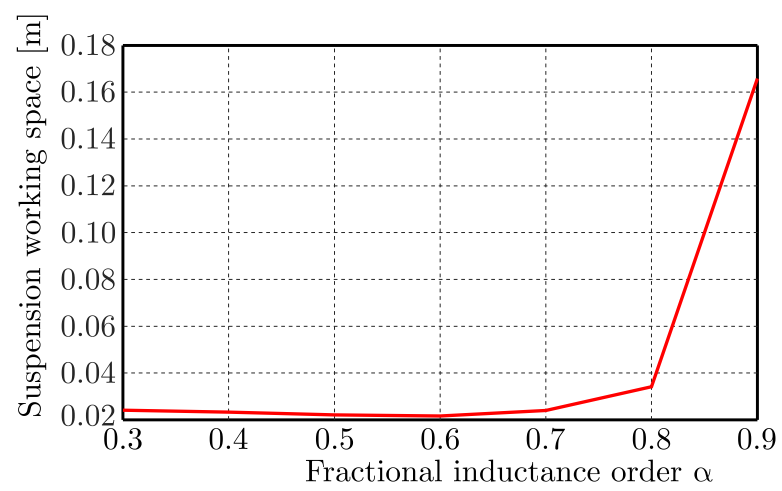

(c)

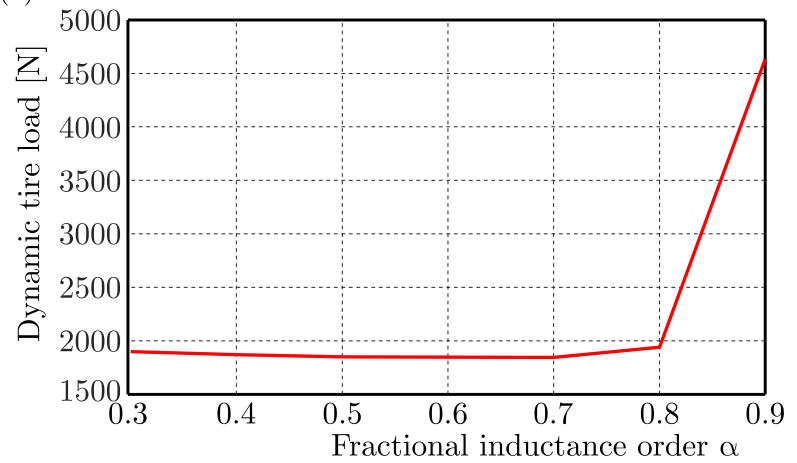

Fig. 9. Impact of the fractional inductance order $\alpha$ on time domain index
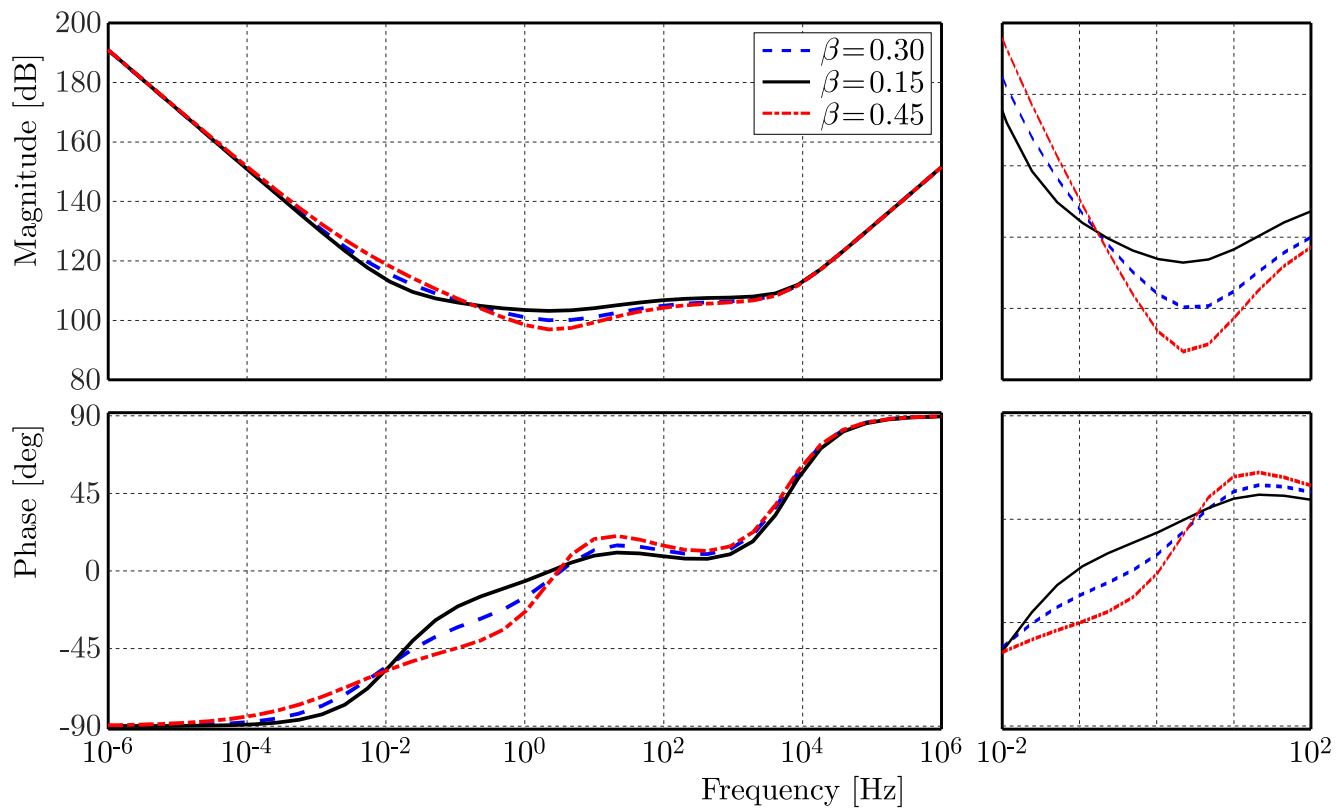

Fig. 10. Comparison of Bode diagrams with different fractional capacitance orders

fractional capacitance order $\beta$ is 0.3 , and the RMS values of body acceleration and dynamic tire load reach the average level when the fractional capacitance order $\beta$ is 0.3 . This time, the suspension performance reaches a local optimization according to the simulation results. 

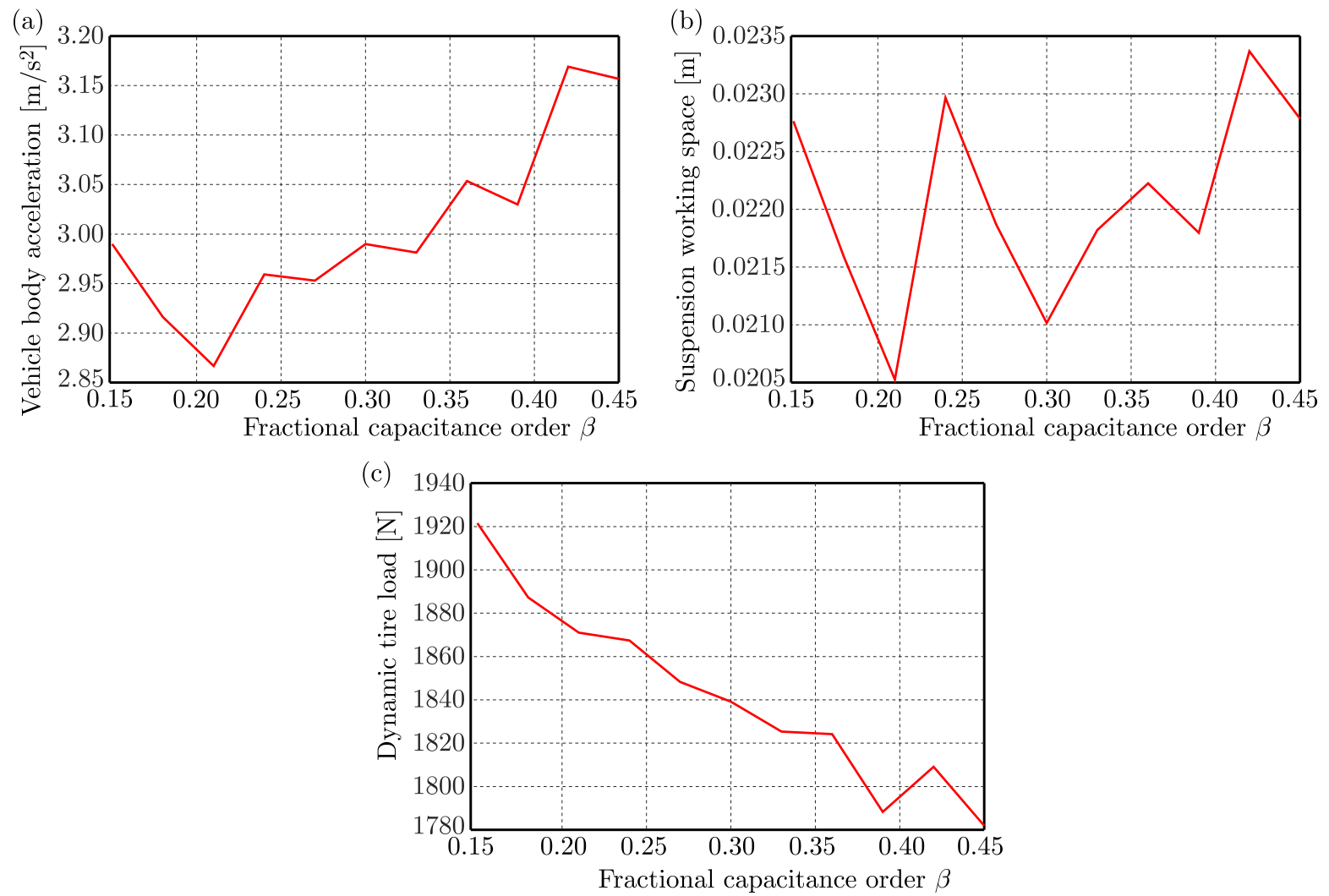

Fig. 11. Impact of the fractional capacitance order $\beta$ on the time domain index

\section{Conclusion}

In this paper, the definition of fractional calculus and mechatronic inerter are introduced firstly, and a quarter dynamic model of fractional-order vehicle mechatronic ISD suspension is established. The superiority of the proposed model is verified by optimization simulation. Then, the influence of the parameter perturbation on the suspension performance is analyzed. The results show that the change of inertance $b$ has a more obvious impact on the vehicle suspension performance when the frequency is above $10^{3} \mathrm{~Hz}$, while the fractional inductance order $\alpha$ and the fractional capacitance order $\beta$ play a significant role in a lower frequency range than the inertance $b$. And it turns out that the frequency range for which the fractional inductance order $\alpha$ and the fractional capacitance order $\beta$ have an important role is within $10^{-2} \mathrm{~Hz}$ to $10^{2} \mathrm{~Hz}$. The research results have certain engineering guiding significance for the parameter design of fractional order suspensions.

\section{Acknowledgement}

This work is supported by National Natural Science Foundation (grant No. 52002156, 52072157), Natural Science Foundation of Jiangsu Province (grant No. BK20200911), the China Postdoctoral Science Foundation (grant No. 2019M651723, 2020M671355), Research Project of the State Key Laboratory of Mechanical System and Vibration (Grant No. MSV202106), the project of the Key Laboratory of Road Construction Technology and Equipment (Chang'an University), MOE (grant No. 300102251502).

\section{References}

1. Chen M.Z.Q., Hu Y.L., Huang L.X., Chen G.R., 2014, Influence of inerter on natural frequencies of vibration systems, Journal of Sound and Vibration, 333, 7, 1874-1887 
2. Chen Y.D., Xu J., Tai Y.P., Xu X., Chen N., 2020, Critical damping design method of vibration isolation system with both fractional-order inerter and damper, Mechanics of Advanced Materials and Structures, 1-12

3. Fu Z.J., Dong X.Y., 2021, Hळ optimal control of vehicle active suspension systems in two time scales, Automatika, 62, 2, 284-292

4. He J., Liu Z.T., ZhAng C.F., 2020, Sliding mode control of lateral semi-active suspension of high-speed train, Journal of Advanced Computational Intelligence and Intelligent Informatics (JACIII), 24, 7, 925-933

5. He L.D., LiU Y.Z., Han S.L., 2017, Comparative study between two schemes of active-control-based mechatronic inerter, MATEC Web of Conferences, 95, 1-4

6. Huang C., Chen L., Jiang H.B., Yuan C.C., Xia T., 2014, Fuzzy chaos control for vehicle lateral dynamics based on active suspension system, Chinese Journal of Mechanical Engineering, 27, 4, 793-801

7. Karthik M., James M.M., 2018, Low-rate characterization of a mechanical inerter, Machines, 6, $3,1-23$

8. Li X.P., Li F.J., ShAng D.Y., 2021, Dynamic characteristics analysis of ISD suspension system under different working conditions, Mathematics, 9, 12, 1345-1345

9. Liu X.F., Jiang J.Z., Titurus B., Farrison A., 2018, Model identification methodology for fluid-based inerters, Mechanical Systems and Signal Processing, 106, 479-494

10. Liu Y.L., Zhao W.T., Yang X.F., Chen L., Shen Y.J., 2019, Predictive control of vehicle ISD suspension based on a hydraulic electric inerter, Shock and Vibration, 2019, 5, 1-11

11. Memlikai E., Kapoulea S., Psychalinos C., Baranowski J., Bauer W., Tutaj A., PiAzTEK P., 2021, Design of fractional-order lead compensator for a car suspension system based on curve-fitting approximation, Fractal and Fractional, 5, 2, 46-46

12. NGuyen S.D., LAm B.D., Choi S.B., 2021, Smart dampers-based vibration control - Part 2 : Fractional-order sliding control for vehicle suspension system, Mechanical Systems and Signal Processing, 148, 1-24

13. Papageorgiou C., Houghton N.E., Smith M.C., 2009, Experimental testing and analysis of inerter devices, Journal of Dynamic Systems, Measurement, and Control, 131, 1, 101-116

14. Papageorgiou C., Smith M.C., 2005, Laboratory experimental testing of inerters, Proceedings of the 44th IEEE Conference on Decision and Control, and the European Control Conference, $3351-3356$

15. Podlubny I., 1999, Fractional Differential Equations, London, Academic Press

16. Shen Y.J., Liu Y.L., Chen L., Yang X.F., 2019a, Optimal design and experimental research of vehicle suspension based on a hydraulic electric inerter, Mechatronics, 61, 12-19

17. Shen Y.J., Shi D.H., Chen L., Liu Y.L., Yang X.F., 2019b, Modeling and experimental tests of hydraulic electric inerter, Science China (Technological Sciences), 62, 12, 2161-2169

18. Siami A., Karimi H.R., 2020, Modelling and identification of the hysteretic dynamics of inerters, Designs, 4, 3, 27-27

19. Sмiтh M.C., 2002, Synthesis of mechanical networks: the inerter, IEEE Transactions on Automatic Control, 47, 10, 1648-1662

20. Swift S.J., Smith M.C., Glover A.R., Papageorgiou C., Gartner B., Houghton N.E., 2013, Design and modelling of a fluid inerter, International Journal of Control, 86, 11, 2035-2051

21. WagG D.J., PEI J.S., 2020, Modeling a helical fluid inerter system with time-invariant mem-models, Structural Control and Health Monitoring, 27, 10, n/a-n/a

22. WAng F.C., Chan H.A., 2011, Vehicle suspensions with a mechatronic network strut, Vehicle System Dynamics, 49, 5, 811-830 
23. Wang F.C., Hong M.F., Lin T.C., 2011, Designing and testing a hydraulic inerter, Proceedings of the Institution of Mechanical Engineers, 225, 1, 66-72

24. Wang R.C., Meng X.P., Shi D.H., Zhang X.L., Chen Y.X., Chen L., 2014, Design and test of vehicle suspension system with inerters, Proceedings of the Institution of Mechanical Engineers, Part C: Journal of Mechanical Engineering Science, 228, 15, 2684-2689

25. Wang R.C., Ye Q., Sun Z.Y., Zhou W.Q., Cao Y.C., Chen L., 2017, A study of the hydraulically interconnected inerter-spring-damper suspension system, Mechanics Based Design of Structures and Machines, 45, 4, 415-429

26. Yan H.J., Qiao J.B., Zhang S., Zhao T., Wang Z.C., 2018, The optimal control of semi-active suspension based on improved particle swarm optimization, Mathematical Models in Engineering, 4, 3, 157-163

27. Zhang H.L., Wang E.R., Zhang N., Min F.H., Subash R., Su C.Y., 2015, Semi-active sliding mode control of vehicle suspension with magneto-rheological damper, Chinese Journal of Mechanical Engineering, 28, 1, 63-75

28. Zhang J.W., Chen S.Z., Zhao Y.Z., 2016, Active suspension with optimal control based on a full vehicle model, Journal of Beijing Institute of Technology, 25, 1, 81-90

Manuscript received August 16, 2021; accepted for print November 30, 2021 